\title{
Engaging learners in STEM education
}

\author{
Joseph Krajcik $^{\text {a1 }}$, İbrahim Delen ${ }^{\mathrm{b}}$ \\ ${ }^{a}$ Michigan State University \\ ${ }^{b}$ Uşak University
}

\begin{abstract}
In this manuscript we focus on how to develop STEM learning environments, and how STEM can be implemented in K-12 schools. We focus on the following question: "How can we support students in building a deep, integrated knowledge of STEM so that they have the practical knowledge and problem solving skills necessary to live in and improve the world?" We also discuss criteria for evaluating STEM learning environments and the challenges teachers face in implementing STEM. We define STEM as the integration of science, engineering, technology, and mathematics to focus on solving pressing individual and societal problems. Engaging students in STEM also means engaging learners in the design process. Design is integral to student thinking in the STEM world. The design process is very non-linear and iterative in its nature but requires clearly articulating and identifying the design problem, researching what is known about the problem, generating potential solutions, developing prototype designs (artifacts) that demonstrate solutions, and sharing and receiving feedback. With the integration of design, STEM education has the potential to support students in learning big ideas in science and engineering, as well as important scientific and engineering practices, and support students in developing important motivational outcomes such as ownership, agency and efficacy. Moreover, students who engage in STEM learning environments will also develop 21st century capabilities such as problem solving, communication, and collaboration skills.
\end{abstract}

Keywords: STEM education, design-based education, learning environments, integrated knowledge, scientific and engineering practices, big ideas of science and engineering

1 College of Education, Michigan State University, 620 Farm Lane, East Lansing, MI 48824, USA; krajcik@msu.edu 


\section{Rationale}

There is no doubt that knowledge of science, technology, engineering and mathematics (STEM) is essential for the future of a sustainable planet. STEM education needs to ensure that the workforce is ready for the challenges and opportunities of the future and that we will live in a sustainable and economically viable world. A STEM literate public needs to make wise choices. Evan Heit, the U.S. National Science Foundation division director for Education and Human Resources Division of Research on Learning, stated that "More effective STEM education requires a deeper understanding of how people learn, from childhood to adulthood" (National Science Foundation, 2016). Moreover, living fulfilling and meaningful lives in the 21st century will require individuals to have a deep, useable knowledge of scientific and engineering ideas and practices, as well as the creativity, problem solving, and communication capabilities and judgment to apply STEM ideas.

STEM permeates our lives. Mobile technology is just one example of how STEM affects our lives, and how different our lives would be if this technology was taken away. How does Wi-Fi work? How is it that our cell phones can transmit audio and video information over such long distances? How do we provide the energy necessary for these devices? Other critical STEM ideas include: How can we reduce carbon emissions in our society and still experience the many comforts of the 21st century, such as car and air travel? New breakthroughs in science, technology, engineering, and medicine have also improved our lives. On April 13th 2016, the New York Times (Carey, 2016) reported that a quadriplegic young man regained some control of movement in his right hand and fingers by using technology that can transmit his thoughts to his hand and finger muscles. The technology, including a chip implanted in the man's brain connected by a computer to a sleeve on his arm, enables him to pour from a bottle and stir using a straw. This breakthrough required the collaborative efforts of individuals from various fields, including computer science, bio-technology, and medicine. These individuals need a profound and practical knowledge in these fields, as well as the imagination and creativity of putting together new ideas.

Although new developments in STEM fields - genetics, nanoscience, neurosciences technology, and engineering - offer unfathomable opportunities for improving human conditions, these and other scientific, technology, and engineering breakthroughs have also given rise to a myriad of global challenges, like water pollution, health concerns related to obesity, climate change, and ethical concerns about genetically modified foods. 
Moreover, the careers that will be available for most children alive today will require a practical knowledge of STEM, the ability to collaborate with others, and the capacity for problem-solving, decision making and innovation. Every child will need to develop a deep and meaningful knowledge of STEM whether they plan to enter the STEM field of work or if they plan to enter other professions. In today's world, we can't escape the use of STEM.

\section{Defining STEM education}

What is STEM education? Whether we call it STEM or STEAM (Science, Technology, Engineering, Art and Mathematics), it is clear that from the US to Korea, science education is moving towards this approach. The National Research Council (2014) defined the steps towards a more integrated STEM approach as connection between activities and materials, connection across disciplines, and measuring and understanding student learning. Another report stated that the criteria for student learning in STEM are defined as engaging in investigations and engineering design projects that are linked to core disciplines and science, mathematics, and engineering practices (National Research Council, 2011a). From robotic activities to creating solutions to real life problems, design is an inevitable component of STEM.

In a previous study, we defined the important steps of the design process by adopting the Fortus, Dershimer, Krajcik, Marx and Mamlok-Naaman's model (2004). In this process, we underlined the role of defining the design problem, exploring the problem, and creating solutions and artifacts (Krajcik \& Delen, 2017). At this stage it is crucial to emphasize that the design does not need to be a physical construct, as the National Research Council 2014 described the outcome as an "engineering or technological design context" (p. 91).

One definition of STEM could be the accumulated knowledge of various science disciplines, technology, engineering, and mathematics as separate but related fields. However, we prefer a more integrative definition of STEM because it mirrors how scientists and engineers work in the world. A richer and more productive manner of thinking about STEM is the integration of science (physics, chemistry, biology, earth and space sciences), engineering, technology, and mathematics to focus on solving pressing individual and societal problems. To accomplish complex tasks such as brain implants, reducing carbon emissions, developing more energy efficient trains, cars and planes, and making use of solar energy, it will be necessary for individuals not only to have a deep usable knowledge in one field, supporting the acquisition of a profound, more useable knowledge, 
but also knowledge in other fields, so that collaborations to solve pressing complex problems can occur. Individuals will also need the creativity to imagine new possibilities and to synthesize ideas. They will also need to know how to collaborate with individuals who have different expertise than they have. Developing an integrated knowledge of STEM is essential in K-12 education, as it lays the foundation for a learner to learn more, solve problems, and innovate.

Our working assumption is that if learning is structured around big ideas of the various fields, which are inherently complex; if knowledge is organized in such a way that it can be used and applied to new contexts; if students use critical thinking, problem solving, collaboration, and communication skills to solve complex problems and make sense of phenomena; and if students learn to be reflective so as to understand how to learn, then they will have a foundation for applying what they know to a lifetime of learning as active participants in a global society. We also have as a main assumption that all students should have high-quality learning opportunities in STEM subjects. Our goal is to foster and develop STEM learners.

Defining STEM as a connection with other disciplines is not a new idea. Examining early AAAS reports, we can see science being defined as a cornerstone or a discipline linked with other disciplines (American Association, 1989). When primarily discussing the links between mathematics, technology, and science, the AAAS report (1989) presents mathematics as the language of science and underlines how fields can contribute to one another. Later this idea led to connecting "science-mathematics-technology and engineering (STEM)" as a way to create a skilled workforce. In the beginning, STEM was implemented in undergraduate programs (Sanders, 2009). When we realized that students were losing their interest in science in earlier grades (Osborne \& Dillon, 2008; National Research Council, 2012; Vedder-Weiss \& Fortus, 2012), STEM gained more momentum by moving into K-12 education, despite the fact that the U.S. Department of Education Office for Civil Rights (2014) shows that only 50\% of the high schools offer calculus, and only $63 \%$ offer physics. The report also underlines the lack of access to core courses (e.g. biology, chemistry, algebra).

In this paper, our goal is not to discuss the paucity in implementing STEM to date; instead we focused on how to develop the STEM learning environment, and how STEM can be implemented. We will primarily focus on the following question: "How can we support students in building a deep, integrated knowledge of STEM so that they have the practical knowledge and problem solving skills necessary to live in and improve the world?" 
In this paper, we will focus on how to design learning environments and develop curriculum resources to promote a deep integrated understanding of STEM across the K-12 spectrum.

\section{Design is a key idea in STEM Education}

Engaging students in STEM also means engaging learners in the design process. Design is integral to student thinking in the STEM world. We modified a model of the design process by Fortus and colleagues (2004) that can be implemented within schools. Design is a unique way of thinking and is critical for students in this society. Design engages learners in finding solutions to problems.

The design process described in Figure 1 below provides a visualization of the design process that can be used in schools. Central to this design process is students clearly articulating and identifying the design problem, researching what is known about the problem, generating potential solutions, developing prototype designs (artifacts) to demonstrate their solutions, and sharing and receiving feedback from their classmates and other knowledgeable persons (see Fortus and colleagues, 2004 for a greater elaboration of each of these steps).

The design process is very nonlinear and iterative in its nature. Although the design process often starts with the identification of a problem, the process can then move in numerous directions from that point onward. Once learners have identified a problem, they could receive feedback on the design problem, or they could research the nature of the problem. Once learners gather information, they could use this information in more clearly specifying their design problem. This specification of the design problem is critical in designing an appropriate solution. Once the design problem is specified, design teams will generate several possible solutions. This would then result in building computer simulations or prototypes testing to see if they meet the criteria of solving the problem. As a result of building and testing a prototype, students will be engaged in analyzing data to see if the prototype met the criteria of the project. The findings from testing the prototype might encourage the students to do more research into the project, which could result in more clearly specifying the problem.

The design process is very iterative in nature. Most learners are not accustomed to engaging in an iterative process and will find it frustrating. All good products and solutions result from iterative design. This iterative process depends on students receiving feedback from testing and analysis, 
but also from comments received from peers and other knowledgeable persons. It is often challenging to receive feedback, but that is what makes a good final product.

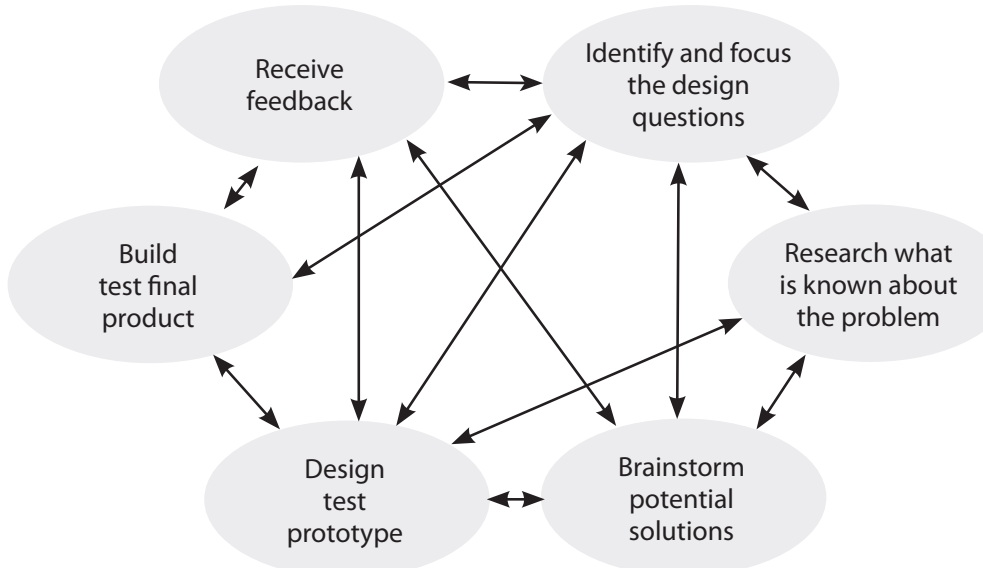

Figure 1. The design-based science learning cycle modified from Fortus and colleagues (2004)

\section{Using the knowledge of how students learn in order to design STEM learning environments}

Learning science, cognitive science, and educational research have contributed key principles in designing STEM learning environments (Krajcik \& Shin, 2014; National Research Council, 2007, 2012; Sawyer, 2014). These principles include: 1) support deep learning of key scientific principles; 2) engage students in making sense of phenomena and designing solutions to problems using scientific and engineering practices, 3) create contexts that motivate and challenge learners, 4) build integrated understanding over time, 5) combine the use of scientific ideas and scientific and engineering practices to develop integrated understanding and 6) make students' thinking visible.

What implications do these major ideas have for the design and development of STEM learning environments and curriculum resources? Learners need to use scientific and engineering ideas and practices, mathematics, and technology to solve problems throughout their K-12 experience to develop an integrated, useable knowledge of STEM. Below we discuss each of these ideas and their implications for the design of STEM learning environments. 


\section{Deep learning of big ideas}

First, the research clearly shows that experts structure their knowledge based on big ideas. While experts have many ideas, it is how these ideas are structured that allows experts to make use of their knowledge to solve problems. It isn't how much they know, but how it is structured that provides experts with their ability to solve problems. Think of a well-structured concept map. It is the ideas and how they are linked together that is critical. Our challenge is to help learners over time develop these integrated maps so that they can solve problems, make decisions, and learn more when needed.

The Framework for K-12 Science Education (National Research Council, 2012) focuses on a limited number of disciplinary core ideas of science and engineering that will eventually allow the development of well structured knowledge. These disciplinary core ideas - or big ideas - are essential to explain and predict a host of phenomena and to solve problems. Disciplinary core ideas are powerful in that they are central to the disciplines of science, serving as thinking tools in making sense of phenomena, and serve as building blocks for learning within a discipline and in making connections to other ideas (National Research Council, 2012; Stevens, Sutherland \& Krajcik, 2009). This focus on core ideas differs from shallow coverage of a large number of topics in existing textbooks (Kesidou \& Roseman, 2002) and allows students to develop an integrated understanding that can be used to solve problems and make decisions. For example, engineers need to make use of various disciplinary ideas in their work as they solve problems. We believe that the K-12 learning environment needs to focus on the big ideas (core disciplinary ideas) of the fields and not on disjointed facts in order to support students in explaining phenomena and designing solutions to problems.

STEM experiences that emphasize design also focus on connecting students' scientific ideas across different disciplines. Honey, Pearson and Schweingruber (National Research Council, 2014), stated that when learners are engaged in STEM activities they "need support to elicit the relevant scientific or mathematical ideas in an engineering or technological design context, to connect those ideas productively, and to reorganize their own ideas in ways that come to reflect normative, scientific ideas and practices" (p. 5).

The recognition of engineering concepts as important science education learning goals is new in the United States. In the Framework for K-12 Science Education, engineering, technology, and applications of science are recognized as disciplinary core ideas on a par with physical science, biological science, and earth and space science ideas. The Framework 
identifies two major disciplinary core ideas in engineering. The first focuses on the engineering design, in which engineers make use of several practices, including problem definition, model development and use, investigation, analysis and interpretation of data, application of mathematics and computational thinking, and determination of solutions to find solutions to problems. Engineering practices incorporate specialized knowledge about criteria and constraints, such as safety, reliability, and aesthetics, and consider social, cultural, and environmental impacts when solving problems; examples of these practices include building physical and computer models to aid in the engineering process, analyzing data that results from prototypes, and optimizing the solution while taking into consideration any trade-offs. The second disciplinary core idea focuses on interconnections among engineering, technology and science, and society. Often new findings from science will catalyze the emergence of new technologies and their applications. At the same time, new technologies provide opportunities for new scientific investigations. Moreover, as we discussed above, advances in science, engineering, and technology have profound effects on human society, in such areas as health, climate, and the natural environment.

Table 1 provides a summary of the DCIs in the Framework for $\mathrm{K}-12$ Science Education. Think of the disciplinary core ideas as the big ideas of disciplines that drive expert thinking (Duncan, Krajcik, \& Rivet, 2016).

Table 1. Disciplinary core ideas from the Framework for K-12 Science Education (Duncan et al., 2016; National Research Council, 2012)

\begin{tabular}{|c|c|}
\hline Life Science & Physical Science \\
\hline $\begin{array}{l}\text { LS1: From Molecules to Organisms: } \\
\text { Structures and Processes } \\
\text { LS2: Ecosystems: Interactions, Energy, and } \\
\text { Dynamics } \\
\text { LS3: Heredity: Inheritance and Variation of } \\
\text { Traits } \\
\text { LS4: Biological Evolution: Unity and } \\
\text { Diversity }\end{array}$ & $\begin{array}{l}\text { PS1: Matter and Its Interactions } \\
\text { PS2: Motion and Stability: Forces and } \\
\text { Interactions } \\
\text { PS3: Energy } \\
\text { PS4: Waves and Their Applications in } \\
\text { Technologies for Information Transfer }\end{array}$ \\
\hline Earth \& Space Science & Engineering \& Technology \\
\hline $\begin{array}{l}\text { ESS1: Earth's Place in the Universe } \\
\text { ESS2: Earth's Systems } \\
\text { ESS3: Earth and Human Activity }\end{array}$ & $\begin{array}{l}\text { ETS1: Engineering Design } \\
\text { ETS2: Links Among Engineering, } \\
\text { Technology, Science, and Society }\end{array}$ \\
\hline
\end{tabular}

Note. LS - Life Science, PS - Physical Science, ESS - Earth and Space Science, ETS - Engineering \& Technology 
The Framework also contains other big ideas that are not unique to a discipline but which are important to all the disciplines. These big ideas are called crosscutting concepts. These crosscutting concepts consist of major scientific ideas that are used in every discipline but at the same time are essential to each discipline as they are needed to make sense of phenomena or find solutions to problems. Cause and effect; systems; patterns; size, proportionality and scale; and matter and energy are examples of crosscutting concepts.

Table 2 presents the list of crosscutting concepts. Crosscutting concepts are critical when solving problems: how does energy flow within a system? Similar to disciplinary core ideas, crosscutting concepts support the process of solving problems and making decisions. To develop the usability of the crosscutting concepts, they need to be made explicit in curriculum resources. Often it is assumed that students understand these concepts, but they are challenging for students to learn and apply. For instance, scale, cause and effect, and structure and function are ideas critical in nanoscience. Curriculum resources need to explicitly support students in learning these important, but often neglected, scientific ideas.

Table 2. Crosscutting concepts from the Framework for K-12 Science Education (National Research Council, 2012)

\begin{tabular}{l|l}
\hline 1. & $\begin{array}{l}\text { Patterns. Observed patterns that occur in the natural or designed world may, in design } \\
\text { and engineering, prompt questions regarding the relationships and factors that } \\
\text { might have influenced a problem that has occurred or on how to improve a design. }\end{array}$ \\
\hline 2. & $\begin{array}{l}\text { Cause and effect. All events have causes that result in an outcome. A major activity } \\
\text { in science and engineering is investigating what causes something to happen. To } \\
\text { improve a product, engineers need to know what causes a device to fail. Engineers } \\
\text { and scientists need to find the cause for a particular event to happen. }\end{array}$ \\
\hline 3. & $\begin{array}{l}\text { Scale, proportion and quantity. In considering phenomena in the natural world or the } \\
\text { design world, it is critical to know what is relevant at different measures of size, time, } \\
\text { quantity, and energy, and how the difference might impact the behavior of a system. } \\
\text { Changes made to the size of a system can impact the structure of the system. }\end{array}$ \\
\hline 4. & $\begin{array}{l}\text { Systems and system models. Scientists and engineers carefully define the system being } \\
\text { studied. They specify the boundaries and make explicit the model of that system. } \\
\text { When building models, scientists and engineers should examine and test ideas of the } \\
\text { model that would impact phenomena in the natural world or products in the design } \\
\text { world (Damelin, Krajcik, Mclntyre, \& Bielik, 2017). }\end{array}$ \\
\hline 5. & $\begin{array}{l}\text { Energy and matter: flows, cycles and conservation. Energy and the behavior of matter } \\
\text { have an impact on all subjects. Tracking the flow of energy and matter in systems } \\
\text { helps scientists and engineers understand the possibilities and limitations that occur } \\
\text { within the system. }\end{array}$ \\
\hline
\end{tabular}


6. Structure and function. The structure of an object, system, or a living thing determines its properties and functions. For instance, the structure of molecules impacts their properties. Armed with this knowledge, nanoscientists can manipulate atoms to form new molecules with different properties (Stevens et al., 2009).

7. Stability and change. All natural and design systems change over time. Understanding the conditions that make a system stable is critical. Scientists and engineers strive to understand what causes the rate of change in a system or the evolution of a system.

Notice how the various crosscutting concepts also intersect with each other. When exploring how the structure of molecules determines the macro properties of the substance, at least four crosscutting concepts are involved: patterns (properties of the substance), cause and effect (structure determines properties), scale (molecules at the molecular level and properties at the macro level) and structure and function (the structure of the molecules affects the properties of the molecule).

The focus of all STEM-based design projects is to support students in developing a deep understanding of big ideas that can be used as thinking tools to find solutions to other problems or to make sense of phenomena. Systematic efforts to develop core ideas and crosscutting concepts need to occur when developing STEM learning environments.

\section{Engaging in scientific and engineering practices}

The Framework for K-12 Science Education emphasizes that learning science and engineering requires the use of scientific and engineering practices to engage students in doing science and engineering design (STEM). Scientific and engineering practices consist of the multiple ways in which scientists explore and understand the world, and how engineers improve and solve problems of the designed world. Table 3 summarizes the eight scientific practices. Including engineering practices shows the importance of these practices to support students in designing solutions to problems and the importance of using them to support students in learning. These practices are very active, and they describe performances that we would expect students to be capable of doing.

Although the practices are listed sequentially, there is no intention of suggesting a linear order. In fact, think of them more as a recursive process. Also, it is important to realize that the practices work together. Typically, when designing solutions to problems this will involve model building and data analysis. 
Table 3. Science and engineering practices (National Research Council, 2012; Schwarz, Passmore, \& Reiser, 2016)

1. Asking questions (for science) and defining problems (for engineering). To engage in scientific inquiry, learners need to ask and refine questions. To engage in engineering design, learners need to define and refine problems.

2. Developing and using models (science and engineering). Learners, including scientists and engineers, need to construct and use models to examine and explore the natural and the designed world. Scientists construct models to explain phenomena and generate data to predict what might happen in future events. Engineers construct models to determine under what conditions flaws might develop in a product, or to test possible solutions to a problem. We should expect students to construct, evaluate, and refine models through an iterative cycle of comparing their predictions with the real world and then adjusting them to gain an insight into the phenomenon or prototype being modeled. Models are based upon evidence, and when new evidence is uncovered that the models fail to explain, students should modify their models. This is a basic premise of science.

3. Planning and carrying out investigations (science and engineering). When exploring the natural world, learners like scientists need to plan and carry out investigations to examine questions about the natural world. When exploring the design world, students like engineers need to plan and carry out investigations to learn more about the problem.

4. Analyzing and interpreting data (science and engineering). Once data is collected about the natural or designed world, learners, scientists, and engineers need to analyze and interpret data to find patterns that will give a better understanding of the system being studied. Both scientist and engineers make decisions by analyzing and interpreting data. Data does not become evidence until it is used to support a claim.

5. Using mathematics and computational thinking (science and engineering). An important part of science and engineering is specifying the relationships between variables to give a better understanding of the system under study. Specifying relationships allows you to predict and explain outcomes more completely and precisely. Using computers, students collect, analyze, and graph data. Computers deliver calculations and graphs, allowing learners to focus on patterns and relationships. Computers also allow for the manipulation of variables to see how changing one variable impacts the behavior of another variable.

6. Constructing explanations (for science) and designing solutions (for engineering). The essence of science is constructing an explanation of how the natural world works, and for engineers it is to design solutions within the design world. Learners need to engage in developing explanations and designing solutions.

7. Engaging in argument from supporting evidence (science and engineering). All of science depends on the use of arguments. In developing explanations and design solutions, learners need to defend their positions with evidence and, when evidence is presented that contradicts their explanation or design solutions, they need to rework their positions. 
8. Obtaining, evaluating, and communicating information (science and engineering). Reading, interpreting, and evaluating current scientific and technical information is an important practice of science. We should expect learners to do the same when they are trying to make sense of phenomena or design a solution to a problem. As scientists and engineers, students should be expected to communicate their findings in a written and verbal form.

\section{Creating contexts that motivate and challenge learners}

Contextualizing instruction to connect with students' everyday experiences is a critical consideration in designing STEM learning environments. Creating contexts that motivate and challenge learners is a key feature when designing learning environments. A contextualized problem anchors the learning in an important real-world situation and has important consequences. A contextualized problem or question, which we refer to as a driving question, is critical to students being able to see the relevance of their learning. However, students may not see immediately how a question relates to the real world or perceive its consequence. A good problem or driving question presents the opportunity to draw students in and helps them to see how it is related to their lives. In this way, driving questions help contextualize what students will learn, engage a variety of learners, and connect learning goals throughout a unit. Creating a need to know is essential in the design of learning environments that propel student learning. Often in our work, we start by having students experience an engaging or anchoring phenomenon (Krajcik \& Czerniak, 2013). For instance, one could engage learners in building a wind or water turbine connected to a generator to light a bulb. An associated driving question or driving problem might be: How can I illuminate a light bulb using water or wind power?

The learning environments should be organized around driving problems and questions (Delen \& Krajcik, 2016; Krajcik \& Czerniak, 2013) that motivate students to apply the science and engineering ideas that they learn. The classroom resources center around presenting phenomena and design problems based on student experiences, conducting investigations, using technology tools, and reading materials that extend students' first-hand experiences of phenomena and support science literacy.

Klager and his colleagues (2017) demonstrated that a project-based instructional intervention in secondary chemistry and physics had a substantively positive effect on two of the three creativity indicators, compared to business-as-usual instruction. Use of imagination and exploration of different points of view both increased. This makes sense given the emphasis that project-based learning places on arguing, figuring, challenging, trying 
out new ideas, and providing a motivating context. The use of a driving question in a project-based learning environment allowed students to use their imaginations and to think about different approaches to problems, as opposed to being told a "right" answer. Design-based environments, because they are similar to project-based environments, can have the same impact. Overall, project-based and designed-based learning environments promise to foster creative thinking and problem solving among K-12 learners.

\section{Developing learning over a period of time}

Research has demonstrated that learning occurs as an ongoing developmental process. For students to learn challenging ideas takes time as they grapple with challenging ideas (National Research Council, 2007; Sawyer, 2014) and use them to explain phenomena or design solutions to problems. A developmental perspective purposefully builds upon and links students' current understanding to previous understanding in order to form richer and more connected ideas over time (National Research Council, 2007). This approach leads to the development of a studens' more sophisticated and integrated understanding of a scientific idea (Corcoran, Mosher, \& Rogat, 2009; National Research Council, 2007). However, the growth in understanding is not developmentally inevitable, but depends on instruction and key learning experiences (including assessments), in both formal and informal environments, to support students as they gradually develop a more sophisticated and integrated understanding (Corcoran et al., 2009). If we have learned anything in the past several years, it is the importance of coherently building and assessing ideas to help learners form integrated understandings (Roseman, Stern, \& Koppal, 2010). This developmental perspective is necessary to help all learners develop a deep knowledge of STEM for the 21 st century. A developmental perspective is especially appropriate for STEM learning experiences, because STEM experiences grow in complexity and sophistication. As such, designers of STEM curriculum materials need to engage learners in linking ideas previously learned to new ideas. In this way, students will be able to solve more complex problems over time.

\section{Integrating practices and big ideas to solve problems and make sense of phenomena}

An underlying premise of situated learning (Greeno \& Engestrom, 2014; National Research Council, 2007) states that all students develop a deeper understanding when constructing knowledge by working with and using 
ideas in real-world contexts. To develop useable knowledge, an individual needs to engage in disciplinary ideas along with practices, and to learn practices by engaging in disciplinary content. We define useable knowledge as having an integrated knowledge structure to solve problems, making sense of phenomena, and learning more when needed. To form useable knowledge, knowing and doing cannot be separated, but must be learned in an integrated fashion. This is the premise that provides support for the use of scientific and engineering practices (SEPs), disciplinary core ideas, and crosscutting concepts working together to make sense of phenomena or find solutions to problems (National Research Council, 2012). Just as science is both a body of knowledge and the process whereby that body of knowledge is developed, so too is the learning of science: you cannot learn a scientific idea without using it with scientific practices. The converse also applies: you can't learn a practice separate from the scientific idea. If we want learners to be able to apply the scientific idea, then they need to engage with that idea utilizing a particular scientific practice, and if we want students to learn the scientific practice, then we need to use the practice to engage with the scientific idea. The integration of the three dimensions of practices, core ideas, and crosscutting concepts is referred to as three dimensional learning.

Supporting students in learning about science and engineering involves the coupling or integration of scientific ideas (disciplinary core ideas and crosscutting concepts) with scientific and engineering practices to build deep, useable knowledge necessary for understanding the physical world in which we live, and for preparing students for STEM careers. The literature provides evidence that understanding a scientific idea is inextricably linked to the context in which the student develops the understanding (National Research Council, 2007). To learn STEM, students need to be engaged in doing STEM.

\section{Making student thinking visible}

Our work also engages students in the building of artifacts that provide a physical representation of the design solution and meet the characteristics specified by the project and elaborated by the group. To build artifacts, students work together in collaborative teams. This would include building the apparatus to accomplish the task (i.e., lighting a bulb or ringing a bell as the result of a series of energy transfers). The building of external artifacts can lead to deeper knowledge; just as important, it can also lead to a sense of personal ownership as students become the designers (Fortus et al., 2004). 
Throughout STEM units, the focus on designing solutions to problems requires students to create, modify, and improve their artifacts (design solution), building deeper and more sophisticated science knowledge. Engaging learners in building artifacts that represent their design solution promotes not only deeper knowledge but also important motivational goals such as ownership and efficacy (Fortus \& Krajcik, 2015).

When finding a solution to problems, students develop a series of artifacts or products that address the question or problem. As part of the design process, students analyze and interpret data and support their design solutions. As such, engaging in design-based research stands apart from other forms of science teaching in that it situates the learning of science in students doing science to find solutions to questions and problems that they find meaningful. As a result, it shifts the responsibility of learning to the student. The artifacts that students build also serve as important embedded assessments that provide insight into students' emerging understanding.

Because artifacts or products show what students have learned, they can be used as forms of assessment of students' understanding of science (Krajcik \& Shin, 2014). Design-based research results in students creating artifacts that address the design problem and show what students have learned. Often, teachers have students share their artifacts with other class members and with teachers, parents, and members of the community. We refer to the products that students construct as artifacts because, like historical artifacts, they serve as objects and records of students engaging in science. When learners build a product, they not only learn more, they also develop ownership of that product, and agency that they can use their knowledge to get something done.

The creation and sharing of artifacts serves several purposes. First, artifacts are real and motivating. Presenting an artifact to an audience of peers, professionals, and community members provides an outcome for the process and gives students an opportunity to talk with others about their work. Second, artifacts help students develop and represent understanding. Because artifacts (such as models, reports, videotapes, new products, and computer programs) are concrete and explicit, they can be shared and critiqued. Such feedback permits learners to reflect, extend their understanding, and revise their work. Third, artifacts allow students to show what they have learned throughout the design process, and they document broad learning - sometimes over an entire school year. Because artifacts show learning over time, they track how student understanding develops. 


\section{Design from a new perspective: technological design}

Technology tools can help transform the STEM classroom into an environment in which learners actively construct knowledge (National Research Council, 2011b; Novak \& Krajcik, 2005; Songer, 2007). Technology tools should be used to support students in design-based education. Using technology tools in STEM education makes the environment more authentic and relevant to students. The students can use technology to access real data on the web, expand interaction and collaboration with others via networks, use computer programs to build prototypes, create games that can be played with others, develop models to test solutions, employ graphing and visualization tools to analyze data, and produce multimedia artifacts and develop programs to run various devices. These are activities that they see and read about professionals doing. In addition, the multimodal and multimedia capabilities of technology make information more accessible, not only physically (by providing easy access to information) but intellectually (by helping students incorporate new information into their understanding).

In order to create their own designs, students first need to develop their models. The Building Models ${ }^{2}$ project offers a practical way to assist students and teachers. In this project, Michigan State University and the Concord Consortium collaborated to explore how students can build dynamic models by continuously evaluating the outputs. When engaging in STEM, it is crucial that students develop and test different models. Technology can help educators find a more affordable solution to this problem, and we will add two more free tools to the list.

LEGO has been a popular component of STEM activities, and there is a free option to use it. Google Chrome and LEGO have built a website (https://www.buildwithchrome.com) that enables students to create their own design. Because this is a free tool, what students can accomplish on the website is limited, but it supports building a variety of structures, and it is a great tool for early STEM users. Designs on the website can be linked to a student's location, so students around the world can compare their models and see what others have done.

In more advanced levels of STEM, teachers can add another website to the list (http://www.algodoo.com/). Algodoo supports creating 2D interactive simulations. By using Algodoo, students can create models of cars, combustion engines, dams, or human anatomy. Despite putting physics at the center, Algodoo is a very powerful tool for teaching science. By using it, students can focus on plenty of big ideas, including forces, light, and energy transfer.

Visit https://concord.org/projects/building-models for more information about the project. 


\section{Criteria for evaluating STEM learning environments}

In recent years, U.S. News \& World Report started new criteria for rating high schools. One of the best STEM high schools put engineering right at the center, and focused on engaging students with architecture and computer integrated manufacturing. Another school listed in the top 5 focused on students' innovation when combining mathematics, science, and technology. What we see across these schools is that they all support student creativity. One popular activity in this process is robotics competition. Currently, The National Aeronautics and Space Administration (NASA) supports more than twenty robotics competitions, ranging from underwater robots to testing a fuel cell system.

Table 4. Criteria for evaluating STEM learning environments

\begin{tabular}{|c|c|}
\hline 1. & $\begin{array}{l}\text { The number of, and the enrollment in, different types of STEM schools and programs } \\
\text { in each district. }\end{array}$ \\
\hline 2. & Time allocated to teach science in grades K-5. \\
\hline 3. & Science-related learning opportunities in elementary schools. \\
\hline 4. & $\begin{array}{l}\text { Adoption of instructional materials in grades K-12 that embody the Common Core } \\
\text { State Standards for Mathematics and a Framework for K-12 Science Education. }\end{array}$ \\
\hline 5. & $\begin{array}{l}\text { Classroom coverage of content and practices in the Common Core State Standards } \\
\text { and the Framework for K-12 Science Education. }\end{array}$ \\
\hline 6. & Teachers' science and mathematics content knowledge for teaching. \\
\hline 7. & Teachers' participation in STEM-specific professional development activities. \\
\hline 8. & $\begin{array}{l}\text { Instructional leaders' participation in professional development on creating } \\
\text { conditions that support STEM learning. }\end{array}$ \\
\hline 9. & Inclusion of science in federal and state accountability systems. \\
\hline 10. & Inclusion of science in major federal K-12 education initiatives. \\
\hline 11. & State and district staff dedicated to supporting science instruction. \\
\hline 12. & $\begin{array}{l}\text { States' use of assessments that measure the core concepts and practices of science } \\
\text { and mathematics disciplines. }\end{array}$ \\
\hline 13. & $\begin{array}{l}\text { State and federal expenditures dedicated to improving the K-12 STEM teaching } \\
\text { workforce. }\end{array}$ \\
\hline 14. & Federal funding for the research identified in Successful K-12 STEM Education. \\
\hline
\end{tabular}


The National Research Council (2013) in the USA identified 14 criteria for judging K-12 STEM education. These criteria are listed in Table 4. The Committee involved in selecting these criteria determined six to be the most important. These are highlighted in bold and italics in Table 4. Notice that time for teaching science in K-5 schools is identified as a key criterion for identifying successful districts in STEM education. This criterion is closely linked to the idea that ideas develop across time. Science is not taught in these grade levels, but to improve student learning of STEM, experiences are critical in the elementary grades. This causes stress on teachers to acquire knowledge of the subject matter. We will need effective teacher preparation and professional learning programs for STEM education to succeed. Teachers will need a deep knowledge of science and also an understanding of what it really means to do science and engineering. Teachers at all grade levels will need to participate in the practice of science and engineering, in the same way as their students.

Notice that one of the critical criteria listed is the importance of funding to support STEM education. STEM education will only be successful if funded by governments. STEM environments need space and they need resources.

\section{Challenges of incorporating STEM education}

Implementing STEM education and design in classroom teaching will pose challenges for teachers. Below we summarize the major challenges that teachers, administrators and school districts will face when implementing STEM education (Krajcik \& Delen, 2017; Sadler, Coyle, \& Schwartz, 2000).

1. Define clear and specific learning goals that allow students to use their knowledge when finding solutions to a problem and making sense of phenomena. By not focusing on learning goals, students will only be involved in activities and, while the activities might be enjoyable, they will not lead to students solving real world problems or learning new ideas in the future.

2. Express the design challenge that students need to accomplish in a clear and concise language. Clarity of the design challenge will support learners in accomplishing both the design goal and the learning outcomes. Opportunities will also be needed for students to refine and further specify the design challenge. To create learning environments that will motivate learners to persevere at solving a challenging problem, they need to be invested in the process. They can gain ownership and investment by refining the problems. 
3. Create motivating and engaging design challenges for students. We need to be sensitive to the backgrounds that different learners bring to classrooms. Some students will be more motivated than others when it comes to design challenges. We need to help learners understand why the problem is important to solve.

4. Develop prototype designs that students can improve upon to help develop students' construction skills and confidence in the design process. As students build new iterations of their devices, they become more sophisticated and show improved performance. Typically in classrooms, science and mathematics teachers at all grades are not accustomed to students building products as a measure of their knowledge. But if we want to engage learners in the design process, then we also need to provide time for students to learn how to use various tools.

5. Allow for multiple iterations that will enable students to modify and test their devices. As pointed out in the design process (Figure 1), a critical part of design is to receive feedback both from individuals and from testing, and then to use this feedback to rework the product. Learners as well as teachers are not used to developing several iterations of a product. But it is through iteration that a designer improves the product, solves the problem better, and learns more.

6. Incorporate scaffolds to support students in becoming familiar with design procedure. Designing is a challenging process, and students will need to be scaffolded in the process. For instance, learners will need support in developing prototype models to test their solutions.

7. Provide students the opportunity to perform multiple iterations. Engaging in multiple iterations also means that as teachers we need to support the acceptance of design failures. Designing solutions to problems is challenging, and at first students will fail as their designs might not meet the specifics.

8. Increase the design performance of students by connecting the design process with the science underlying it. If we hope that students will learn from engaging in design, then learners need to make visible the underlying science ideas behind their design. Engineers have a deep knowledge of science disciplines. Would you trust giving a several million dollar contract to an individual to build a bridge if they did not understand forces or materials?

9. Construct observation protocols to formatively assess students as they engage in the design process. Formative assessment is critical to improve students' skills in design, collaboration, and communication. Students need to present the artifacts to various audiences and receive feedback 
on their work. This has three major benefits for learners: 1) learners see that what they do in school is important and valuable to others, 2) learners receive feedback on their work, and 3) learners communicate about their solutions to problems.

10. Make sure that students have the opportunity to present and receive feedback on their designs. Presenting and receiving feedback takes time, but it is a critical aspect of the design process.

\section{Examples of STEM and the design process}

Up to this point we have primarily summarized two big ideas: (1) how STEM permeates our lives, and (2) the importance of designing STEM environments to support deep learning of big ideas over time, to engage learners in the design process by emphasizing scientific and engineering practices, and to create contexts that motivate and challenge learners. Below, we present two STEM examples from students and an enthusiastic teacher that elaborate on the ideas of design and STEM education.

An enthusiastic science teacher, Burhan Zenginsan, plays with cardboard, silicone, empty bottles, and plastic pipes when teaching forces, energy transfer and aerodynamics (see Figure 2). He gives his students cardboard and asks them to design paper rockets (engaging learners in the design process with an emphasis on scientific and engineering practices). Each student makes their design by cutting their cardboard and gluing it using silicone. Then the teacher places the rocket on top of a plastic pipe that is connected to an empty water bottle. In the final step, students jump on the water bottle and observe which rocket can go higher (contexts that motivate and challenge learners). Here, a simple plastic pipe mechanism connected to a paper rocket and a plastic bottle shows how the energy generated by a student's jump is transferred. The force applied by the student changes how high the cardboard rocket can reach. Students first test how applying different forces would change the height of the paper rocket. Later they compare how different designs (e.g. each student is asked to design different wings) can influence the height the paper rocket can reach (deep learning of big ideas over time.) Students need to demonstrate their understanding of the experiment by giving explanations as to why the rocket travels in the way that it does.

The second example concerns robots. We all know that robots make our life easier, but who would think that robots could save a puppy? In Istanbul, a small dog fell into a hole that led to a $70 \mathrm{~m}$ (230 feet) water well. When 
people heard the noise, they called the nearest fire-station. Since the dog was afraid and did not co-operate with firefighters for about 10 days, the only option left was to feed the dog and observe it using thermal cameras. On the 10th day, STEM came to the rescue, when high school students developed a robotic arm, placed it around the dog, and pulled the dog back to the surface (Hurriyet Daily News, 2017).

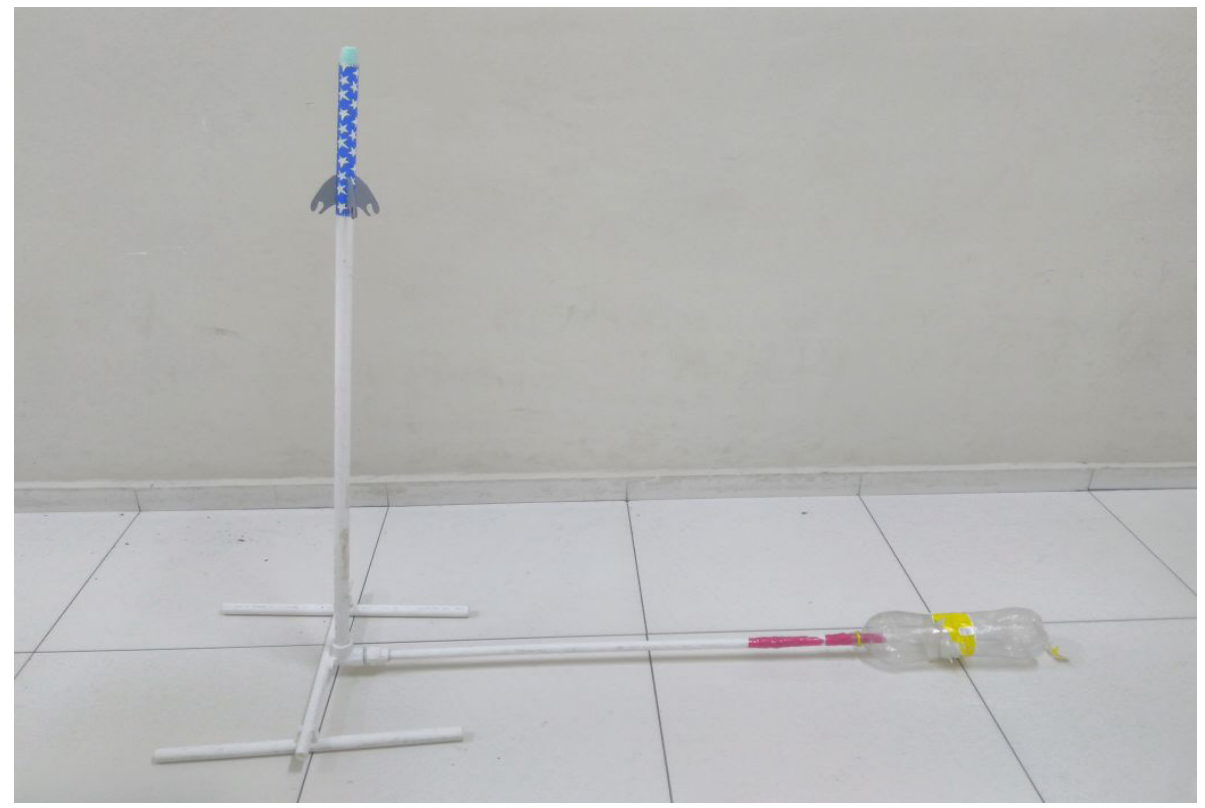

Figure 2. Paper Rocket Model

\section{Concluding comments}

STEM education that focuses on design has the potential to support students in learning big ideas in science and engineering, as well as important scientific and engineering practices. Design environments also support students in developing important motivational outcomes such as ownership, agency and efficacy. Moreover, students who engage in the design process will also develop 21st century capabilities such as problem solving, communication, and collaboration skills.

K-12 classrooms need to support students in STEM and design-based education to help them meet important learning goals essential to the world in which they live. Engaging K-12 STEM will require shifts in teaching practices and new ways of thinking, but the benefits of meeting these challenges will help to ensure that K-12 learners have the knowledge-in-use 
they need to live and help this world prosper. Such experiences will help prepare the learners of today to invent the solutions of tomorrow, perhaps finding solutions to renewable and clean energy sources that can be of use to all countries in the world. Our goal in STEM education should be to empower learners with the knowledge and ability to solve challenging problems. Having the knowledge and sense of self that "I can do it" is critical in helping all learners develop into 21st century citizens. All K-12 students throughout the world need to experience the joy of discovery and innovation when solving problems and building a product that will benefit future generations.

\section{References}

American Association for the Advancement of Science (1989). Science for all Americans. Washington. Retrieved from http://www.project2061.org/publications/sfaa/online/sfaatoc.htm.

Carey, B. (2016, April). Chip, implanted in brain, helps paralyzed man regain control of hand. The New York Times. Retrieved from http://www.nytimes.com/2016/04/14/ health/paralysis-limb-reanimation-brain-chip.html?_r=0.

Corcoran, T. B., Mosher, F. A., \& Rogat, A. (2009). Learning progressions in science: An evidence-based approach to reform (CPRE Report). New York: Columbia University.

Damelin, D., Krajcik, J., McIntyre, C., \& Bielik, T. (2017). Students making system models: An accessible approach. Science Scope, 40(5), 78-82. https://doi.org/10.2505/4/ss17_040_05_78

Delen, I., \& Krajcik, J. (2016). Using mobile devices to connect teachers and museum educators. Research in Science Education, 1-24. https://doi.org/10.1007/s11165-015-9512-8

Duncan, R., Krajcik, J., \& Ravit, A. (2016). Disciplinary core ideas: Reshaping teaching and learning. Arlington: National Science Teachers Association Press.

Fortus, D., Dershimer, C. R., Krajcik, J., Marx, R. W, \& Mamlok-Naaman, R. (2004). Design-based science and student learning. Journal of Research in Science Teaching, 41(10), 1081-1110. https://doi.org/10.1002/tea.20040

Fortus, D., \& Krajcik, J. (2015). Engineering in IQWST. In C. Sneider (Ed.), The go-to guide for engineering curricula grades 6-8: Choosing and using the best instructional materials for your student. Thousand Oaks: Corwin Press.

Greeno, J. G., \& Engestrom, Y. (2014). Learning in activity. In R. K. Sawyer (Ed.), The Cambridge handbook of the learning sciences (2nd ed., pp. 128-147). New York: Cambridge University Press.

Hurriyet Daily News (2017). Puppy stuck in well rescued after 10 days in Istanbul. Retrieved from http://www.hurriyetdailynews.com/puppy-stuck-in-well-rescuedafter-10-days-in-istanbul.aspx?pageID=238\&nID $=109770 \&$ NewsCatID $=378$.

Kesidou, S., \& Roseman, J. E. (2002). How well do middle school science programs measure up? Findings from Project 2061's curriculum review. Journal of Research in Science Teaching, 39(6), 522-549. https://doi.org/10.1002/tea.10035 
Klager, C., Schneider, B., Krajcik, J. S., Lavonen, J., \& Salmela-Aro, K. (2017). Creativity in a project-based physics and chemistry intervention. Paper presented the annual meeting of NARST, April, 2017, San Antonio, Texas.

Krajcik, J. S., \& Czerniak, C. (2013). Teaching science in elementary and middle school classrooms: A project-based approach (4th ed.). London: Routledge.

Krajcik, J., \& Delen, I. (2017). How to support students in developing usable and lasting knowledge of STEM. International Journal of Education in Mathematics, Science and Technology, 5(1), 21-28. https://doi.org/10.18404/ijemst.16863

Krajcik, J. S., \& Shin, N. (2014). Project-based learning. In R. K. Sawyer (Ed.), The Cambridge handbook of the learning sciences (2nd ed., pp. 275-297). New York: Cambridge University Press.

National Research Council (2007). Taking science to school: Learning and teaching science in grades K-8. Washington: The National Academies Press.

National Research Council (2011a). Successful K-12 STEM Education: Identifying Effective Approaches in Science, Technology, Engineering, and Mathematics. Washington: The National Academies Press.

National Research Council (2011b). Learning science through computer games and simulations. Washington: The National Academies Press.

National Research Council (2012). A framework for K-12 science education: Practices, crosscutting concepts, and core ideas. Washington: The National Academies Press.

National Research Council (2013). Monitoring progress toward successful K-12 STEM education: A nation advancing? Washington: The National Academies Press.

National Research Council (2014). STEM integration in K-12 education: Status, prospects, and an agenda for research. Washington: The National Academies Press.

National Science Foundation (2016, December). NSF awards $\$ 61$ million in new projects to enhance understanding of STEM education and workforce development. Retrieved from https://www.nsf.gov/news/news_summ.jsp?cntn_id=190509.

Novak, A., \& Krajcik, J. S. (2005). Using learning technologies to support inquiry in middle school science. In L. B. Flick \& N. G. Lederman (Eds.), Scientific inquiry and nature of science: Implications for teaching, learning, and teacher education. Dordrecht: Kluwer Academic Publishers.

Osborne, J. F., \& Dillon, J. (2008). Science education in Europe: Critical reflections. A Report to the Nuffield Foundation. Retrieved from http://www.nuffieldfoundation.org/sites/default/files/Sci_Ed_in_Europe_Report_Final.pdf.

Roseman, J. E., Stern, L., \& Koppal, M. (2010). A method of analyzing the coherence of high school biology textbooks. Journal of Research in Science Teaching, 47(1), 47-70. https://doi.org/10.1002/tea.20305

Sadler, P. M., Coyle, H. P., \& Schwartz, M. (2000). Engineering competitions in the middle school classroom: Key elements in developing effective design challenges. The Journal of the Learning Sciences, 9(3), 299-327. https://doi.org/10.1207/S15327809JLS0903_3

Sanders, M. (2009). STEM, STEM education, STEM mania. The Technology Teacher, 68(4), 20-26.

Sawyer, R. K. (Ed.) (2014). The Cambridge handbook of the learning sciences (2nd ed.). New York: Cambridge University Press. 
Schwarz, C., Passmore, C., \& Reiser, B. J. (Eds.) (2016). Helping students make sense of the world using next generation science and engineering practices. Arlington: National Science Teachers Association Press.

Songer, N. B. (2007). Digital resources or cognitive tools: A discussion of learning science with technology. In S. Abell \& N. Lederman (Eds.), Handbook of research on science education (pp. 471-491). Mahwah: Erlbaum.

Stevens, S., Sutherland, L., \& Krajcik, J. S. (2009). The big ideas of nanoscale science and engineering: A guidebook for secondary teachers. Arlington: National Science Teachers Association Press.

U.S. Department of Education Office for Civil Rights (2014). Civil rights data collection. Data snapshot: College and career readiness. Retrieved from https://www2.ed.gov/about/offices/list/ocr/docs/crdc-college-and-career-readiness-snapshot.pdf.

Vedder-Weiss, D., \& Fortus, D. (2012). Adolescents' declining motivation to learn science: A follow-up study. Journal of Research in Science Teaching, 49(9), 10571095. https://doi.org/10.1002/tea.21049. 